\title{
LA COMPETITIVIDAD TERRITORIAL EN LA DESCENTRALIZACIÓN ECONÓMICA DEL PERÚ
}

\author{
TERRITORIAL COMPETITIVENESS IN THE ECONOMIC DECENTRALIZATION \\ OF PERU
}

\begin{abstract}
Tarcisio Andaluz Westreicher
Especialista Legal de la Dirección de Registros Ambientales del Servicio Nacional de Certificación Ambiental para las Inversiones Sostenibles (Senace). Maestría en Gestión Pública de la Facultad de Ciencias Administrativas de la Universidad Mayor de San Marcos. Correo: tarcisioandaluz@hotmail.com (autor corresponsal).
\end{abstract}

[Recibido: 10/12/2016 Aceptado: 16/02/2017]

\section{RESUMEN}

Descentralización, política de Estado y de gobiernos; es también convergencia de discursos de cualquier tendencia ideológica; su expresión territorial: regiones y municipalidades; la tendencia, reducir el número de regiones como panacea; su expresión administrativa, descentralización funcional y sectorial; su expresión fiscal, transferencias tributarias y monetarias; el problema, que a quince años de práctica descentralista y a noventa de teorización, desde Mariátegui, ninguna de sus expresiones se manifestó en modificación de la estructura productiva, en descentralización económica y en competitividad territorial; ello, pese a la mayor autonomía cedida. Mientras, la globalización necesita de ella y de la democracia para legitimar decisiones soberanas y unir diferencias Norte - Sur, centros - periferias. El procedimiento: levantamiento de datos teóricos, legales, institucionales y comparados; confrontados con la actualidad real. Los resultados: la globalización como unión de polos y diferencias; la competitividad, un concepto centralista y centralizador que sólo halla rival en el concepto de competitividad sistémica de MeyerStamer. La tendencia global de agrandar territorios en regiones, contra la tendencia histórica reduccionista; la descentralización por disciplina fiscal incrementó la desinstitucionalización del Estado; la descentralización distributiva de tierras, dinero y funciones sin descentralización económica es poner la carreta delante de los caballos y un remedio peor que la enfermedad.

\section{PALABRAS CLAVE}

Descentralización económica, regionalismo, competitividad sistémica, estructura productiva.

\begin{abstract}
Decentralization, state and government policy; it is also the convergence of discourses of any ideological tendency; its territorial expression: regions and municipalities; the trend, reduce the number of regions as panacea; its administrative expression, functional and sectoral decentralization; its fiscal expression, tax and monetary transfers; the problem, that for fifteen years of decentralist practice and ninety years of theorization, since Mariategui, none of its expressions were manifested in a modification of the productive structure, in economic decentralization and in territorial competitiveness; despite the greater autonomy granted. Meanwhile, globalization needs authonomy and democracy to legitimize sovereign decisions and unite differences in North - South, center- peripheries. The procedure: collection of theoretical, legal, institutional and comparative data; confronted with the actual news. The results: globalization as a union of poles and differences; competitiveness, a centralist and centralizing concept that only finds a rival in Meyer-Stamer's concept of systemic competitiveness. The global tendency to enlarge territories in regions, against the reductionist historical tendency; decentralization through fiscal discipline increased the deinstitutionalization of the state; the distributive decentralization of lands, money and functions without economic decentralization is to put the cart before the horses and a remedy worse than the disease.
\end{abstract}

\section{KEYWORDS}

Economic decentralization, regionalism, systemic competitiveness, productive structure.

Como Citar: Andaluz, T. (2017). La competitividad territorial en la descentralización económica del Perú. Quipukamayoc, 25(48), 101-111. doi: http://dx.doi.org/10.15381/quipu.v25i48.14000

\footnotetext{
(c) Los autores. Este artículo es publicado por la Revista Quipukamayoc, Universidad Nacional Mayor de San Marcos. Este es un artículo de acceso abierto, distribuido bajo los términos de la Licencia Creative Commons Atribución-NoComercial-Compartirlgual 4.0 Internacional.(http://creativecommons.org/licenses/by-nc-sa/4.0/), que permite el uso no comercial, distribución y reproducción en cualquier medio, siempre que la obra original sea debidamente citadas.
} 


\section{INTRODUCCIÓN}

El artículo se corresponde con la temática desarrollada en la tesis para optar la maestría en Gestión Pública por la Facultad de Ciencias Administrativa en la Universidad Nacional Mayor de San Marcos, titulada "Modelos de competitividad territorial en el proceso de descentralización peruano", que trata de las teorías y criterios sobre cómo debe hacerse la demarcación territorial regional y/o sobre las formas y/o condiciones para la descentralización del país. La importancia de analizar críticamente esos dos aspectos del desarrollo territorial peruano, radica en lo mucho que se ha dicho desde los años veinte del siglo pasado y lo poco que se ha logrado en desarrollo territorial equilibrado y la efectividad del desarrollo humano por el proceso de descentralización.

El propósito de la revisión historiográfica es la de asumir y sugerir una posición crítica sobre lo que realmente significa la descentralización, lo que debe ser la regionalización en tanto demarcación territorial y aceptar el reto de que la competitividad puede ser posible en las regiones para producir efectos materiales en el desarrollo humano. Al plantear el problema desde el contexto de diferentes corrientes en los siglos XX y XXI, se pretende dejar constancia de que la "descentralización" y el "regionalismo" son conceptos que tienen valor instrumental para ser utilizada por ideologías e intereses, aun cuando sean opuestas, razón por la que en ausencia de una nueva estrategia nacional, el uso de esos conceptos puede ser útil para incrementar las diferencias territoriales, en el ámbito nacional e internacional.

Por eso, debido a ese valor instrumental, queda abierta la puerta al enten- dimiento de que hay grandes posibilidades de llevar al país al desarrollo con descentralización, previa la restructuración conceptual, primero y reestructuración política, normativa e institucional, después; todos en una nueva cultura del desarrollo territorial nacional, lo que también supone asumir el concepto de competitividad sistémica en sus cuatro niveles (macro, micro, meta y meso) que, entre otros autores, desarrolló Jörg MeyerStamer y que en su sentido más concreto es la expresión de la intergubernamentalidad, la intersectorialidad, la transversalidad con el sector privado y la sociedad civil.

La mayor limitación: la dificultad, de lograr entrevistas con funcionarios de la administración pública vinculados a la materia de estudio, con honrosas excepciones; el objetivo: romper paradigmas, revisar conceptos tradicionalmente aceptados como irrevisables; el criterio de análisis: sometimiento de conceptos a falsación o a reducción al absurdo; el propósito final, establecer nuevos criterios y rescatar la verdadera finalidad de la regionalización y la descentralización: la persona humana como fin supremo de la sociedad y el Estado; el instrumento público: la participación del Estado, el sector privado y la sociedad civil, enderezados hacia la modificación nacional de la estructura productiva, sin más costos que el de la cogestión y la bidireccionalidad económica en la relación salida de recursos naturales y retorno del desarrollo, rescatando la verdadera voluntad ciudadana en materia territorial, nunca expansionista, siempre de reduccionista, que condice con la industrialización descentralizada.

Ochenta y seis años, variantes jurídicas e institucionales de descentralización, dos intentos reales de formar re- giones fracasadas, decenas de criterios para justificar la creación regiones supra departamentales. Cualquier intento que trate de resolver los problemas teóricos sobre porque no funcionó justifica el estudio.

\section{Regionalismo y Centralismo}

Mariátegui (1968), hace 86 años atrás, en su ensayo Regionalismo y Centralismo, indica que las demarcaciones territoriales mayores (regiones, departamentos, estados), no a las municipales, condicionó la creación de regiones y la descentralización a la solución de los problemas económicos de un único sector social, el indio, con una única solución, la tenencia de la tierra en sus manos. Cuando en 1969 la Reforma Agraria distributiva modificó la estructura de la tenencia de la tierra, pasando del hacendado a la comunidad, se pudo confirmar su ineficacia.

Cuando Mariátegui consideró que la reforma agraria liberal, como la yugoeslava, con un máximo de 500 hectáreas/familia era tardía, estaba equivocado, no era tardía, era imposible. Hoy se verifica que la baja productividad de las tierras de la sierra frente a la costa, como lo afirma Maletta (1980) es porque ochenta hectáreas de tierras regadas de la costa pueden equivaler a dos mil de la sierra, una relación $1 / 25$. Asimismo, la reforma liberal en la sierra no era posible, no porque se tratase de un modelo de dominación o burgués, sino por una verdad material más dramática, pero sincera: la población nacional, era de 7 millones y el $70 \%$ andina y rural y las tierras agrícolas en todo el país no pasaba de 2 millones 700 mil hectáreas, la menor cantidad está en la sierra y cada familia hubiera podido acceder a sólo dos quintos de hectárea. 
Entonces, la reforma liberal hubiera evidenciado que la condición socioeconómica de la sierra no era achacable exclusivamente a la tenencia hacendaria, sino a una condición natural, la escasez de tierras y de baja productividad, amén de la distancia del mercado y la incapacidad política de proponer otras formas de desarrollo para esa región natural. La propiedad privada de la tierra, en la sierra, no hubiera podido ser nunca un instrumento de dominación; nadie puede dominar con la propiedad de su pobreza. El desmentido marxista de que ser dueño de los medios de producción es la base diferencial entre los que dominan y los dominados era una delación que no se deseaba admitir. La mejor forma de disimularlo, a costo social de los comuneros, era con propiedad comunal. No se puede contra la verdad material, la propiedad comunal se ha limitado al de los pastos; las tierras agrícolas igual se han parcelado en posesiones de 2/5 hectárea/familia.

Vivanco (2016) afirma que la población ovina ha caído de 14000,000 a 9 000,000 , por no hacer una reorientación genética y productiva y acompañado del proceso de descentralización peor hecho en el Perú y cuya principal víctima es principalmente el sector productivo agrario. Es decir, los pastos se están degradando por la presión antrópica y la explicación a ello la da Garrett Hardin en La tragedia de los bienes comunes. El nuevo problema económico es el problema de la sierra, que requiere de nuevas propuestas.

Después de la Independencia, todo lo español era juzgado malo, por eso, cuando Mariátegui dice el latifundio feudal o semifeudal es constitucionalmente incapaz del progreso técnico, dice una verdad, pues con un factor de producción tan escaso como las tierras de la sierra peruana, sólo había dos modos posibles de producción, la comunal, donde nadie es propietario de nada y la producción se raciona, o la feudal, con soporte de relaciones pre-capitalistas, (el subarriendo de la tierra, a cambio de productos, el compartir los pastos de la hacienda con los pequeños criadores de ovinos a cambio del pastoreo de los propios, la ayuda en casa a cambio de casa, cama y comida, etc.). En esas tierras, distantes, con gente sin necesidad de grandes conocimientos, sin vías, de transportes con acémilas, sin mercados, etc., la incorporación de la técnica no sólo era sociológicamente imposible sino materialmente innecesaria. Nadie quiere producir más si no tiene a quien vender ni cómo llegar al mercado. Por eso, cuando llegó la Reforma Agraria, no se hizo lo que Mariátegui quiso, se hizo lo único que se podía cuando, en el camino, la Reforma cayó en cuenta de que no había suficientes tierras para hacer la reforma liberal.

Hoy sabemos que la propiedad comunal en la sierra sólo puede ser productiva y rentable si hay una conducción empresarial, por ello se ha racionalizado una salida con modelos de conducción por gerencia social como lo indican Tito, Bautista, y Bonilla (2011), camino a soluciones consensuadas, modelo que tiene presencia aislada y no constituye una política de Estado.

En lo referido a la demarcación regional, Mariátegui era detractor de los departamentos, porque decía, descienden de las artificiales intendencias del virreinato. No tienen por consiguiente una tradición ni una realidad genuinamente emanada de la gente.

El pensador, evidencia la influencia de dos tendencias: por su socialismo, creyó que la configuración humana de una región debe determinar su demarcación; por su modernismo republicano, creyó que el federalismo de Estados Unidos era la mejor expresión de la gobernabilidad de un espacio; sin embargo, el federalismo, de origen norteamericano, no nació por tendencia liberal, al contrario, como en Argentina, o como lo quiso Francisco de Carbajal en el Perú virreinal, su tendencia era feudal. El carácter estadual de Estados Unidos, Argentina y la que quería Carbajal, tenían algo en común, ninguno tuvo consideraciones sociales y no pensaron en la comunidad indígena. Si en el Perú se harían regiones sobre la base de la tradición emanada de la gente, no tendríamos 24 departamentos y una provincia constitucional (de origen un tanto inadecuado), tendríamos algo de setenta regiones. Proponer grandes espacios regionales como camino al federalismo, puede parecer participativo y democrático, pero lo participativo y democrático jamás fue para agregar territorios, sino para desagregarse de uno mayor, Es así como se partió de 4 departamentos, desde que San Martín los declaró en Huara cuando el Perú era más grande y tenía a Arica, Tarapacá y Leticia, y se llegó a 24 .

Belaunde (1931) no pudo evitar el tema por necesidad de responder ideológicamente a Mariátegui, a quien, en su libro Realidad Nacional lo acusó de sólo mirar la costa y la sierra, ignorando la selva y, cuando la miró, se limitó a Loreto; pero coinciden en que las regiones son una materia de Historia y Economía y reconoce que en ese enfoque, Mariátegui tiene las virtudes de ser observador y realista; sin embargo, no convienen en que la historia ha demarcado reduciendo, no sumando. Reconoce al federalismo, como utópico y anatópico (que es un neologismo 
acuñado por Belaunde, para referirse a una desviación de la realidad), pero reconoce también que ninguna distribución territorial es perfecta. Hay que ver cuál es la menos mala y elegir ésa. Son expresiones cargadas de verdad, pero no para ver cómo se crearon los departamentos en Francia y los estados federados de Estados Unidos de Norteamérica. En Francia, el criterio fue lo que un caballo podía caminar en un día de extremo a extremo y por eso fueron 92 departamentos en algo más de 600 kilómetros cuadrados. En Estados Unidos, son trazos en papel y por eso se ven esas líneas rectas en su mapa. Sépase entonces, que ni en Estados Unidos, ni en Francia ni en ningún lugar, las demarcaciones mayores se deciden por modelos buenos o malos sino por convencionalismo, que nada tiene de científico, pues están pensados para gobernar territorios, no para hacer ciencia geográfica.

Cuando Belaúnde repite a Mariátegui diciendo que las regiones se piensan para unir lo que estaba dividido y no para dividir lo que estaba unido, no se piensa en que toda demarcación territorial divide lo que estaba unido; toda regionalización, aparentemente, une lo que está separado, pero no se piensa que no es incondicional, nadie se une para ceder poderes, sino para reforzarlos por la sinergia, y si no logra ese propósito, renuncia a él.

Basadre (1995), en su libro Perú Problema y Posibilidad, la idea general no era diferente, pero en las sutiles diferencias con Mariátegui estaban las grandes; pero hallarlas requiere esfuerzos analíticos no comunes en quienes se hipnotizan con las frases. Si Mariátegui pensaba en solucionar el problema del indio, consustancialmente campesino, Basadre prefirió no decir que se oponía a ello, prefirió que lo descubramos. Reconocía la progresividad de los agricultores, pero diferenciaba agricultores de campesinos y afirmaba que el campo es conservador, retrógrado, impasible (...) a veces va a la sublevación negativa, pero no a la Revolución y hasta defiende el pasado (...) no se engarfia lo rural con lo distante, ignora a la Nación y el Estado. Con tales frases ¿podría Basadre esperar la revolución por parte de los comuneros?

Otra forma de oponerse sin oponerse de Basadre fue con lo dicho por Mariátegui y Belaúnde sobre los departamentos. Creyó, como éstos, en la artificialidad de las Intendencias, pero fue el primero en reconocer que los departamentos eran una necesidad. Es que, una vez más, simplemente se trata de un convencionalismo para gobernar, no para hacer geografía.

\section{Demarcación territorial}

Romero (1987), otro de los que creyeron que hay técnicas geográficas para demarcar y hay razones económicas para integrar espacios. Hemos de decir que la demarcación, como lo ha demostrado la historia, es un proceso tan poco técnico que hubieron tantas propuestas para conformar regiones como autores o políticos que pensaron en ello. Lo que sólo viene a confirmar que, al final, se hará como diga un convencionalismo político.

Sin advertir las consecuencias, Romero, al defender las razones por las que Lima es la capital, creó el concepto de "imperativo geoeconómico", pues al referirse a Lima dice que no era una gran capital exclusivamente por razones de preponderancia política, como sede de gobierno y del Parlamento. Lima está en el centro de una concen- tración de grandes valles (...) su situación de gran capital es un imperativo geoeconómico.

Se trata simplemente de un concepto universal que vincula lo geográfico a lo económico, como también lo hace lo social y lo político. Pero mejor tener cuidado, pues si alguien dice "unidad geoeconómica, política y social”, no sabemos cómo vamos a emplear la expresión a materia concreta.

El concepto se incorporó en la Constitución Peruana de 1979 como "unidad geoeconómica” y se repitió en la de 1993; luego, repetido por los todos los intelectuales sin que se defina qué determina su formación ni qué lo delimita. Ahora tenemos que no se sabe si las regiones se forman sobre la base de ellas o para crearlas. Para la Constitución, las regiones se crean sobre la base de éstas, para la Ley de Bases de Regionalización, se crean para formarlas; es decir de una predeterminación real se salta a la voluntaria sin problema alguno, pero como no se dice cómo se delimita, se terminará aterrizando en lo mismo, en el convencionalismo.

Determinista, Romero pretendió dar las presuntas bases técnicas para crear regiones; entonces, con la mejor intención, creó otro concepto que ahora se emplea para justificar una fatalidad, el concepto "equilibrio entre humanidad, tierra y agua”, fue justificado por el autor recurriendo a la triste historia de desarraigo de los mitimaes que él lo presenta como un hecho de planificación. He ahí la justificación de los actuales usurpadores de las tierras del Estado en la Amazonía peruana, los espontáneos "mitimaes" de la sierra que invaden la selva peruana, llena de agua, y de los que invaden la costa, 
sin agua, incrementando el proceso de desertificación por presión antrópica.

Debió decir Romero que ese equilibrio es bueno cuando se lleva el agua donde está la tierra y después llevar al hombre a esas tierras, pero el expediente más fácil ha sido llevar al hombre donde está el agua, que por verdad geográfica del Perú, está donde están las peores tierras, precisamente, la selva. Mal entendido Romero, fue creído como parte de una verdad popular y gente, políticos e intelectuales han creído que la selva es la despensa del Perú, creencia basada en la ignorancia y repetida desde Manuel Pardo, Belaúnde y pueblo en general. Spahni (1971) llegó a proponer como necesidad el traslado masivo de habitantes de la sierra hacia la selva. Los políticos, todos presuntamente conservacionistas, ninguno ecologista, repitieron la falsedad y hoy la usurpación de la selva con ocupación de 150 mil hectáreas por año, con un balance de 10 millones de hectáreas deforestadas, es resultado de llevar gente donde está el agua para no llevar agua donde está la tierra seca.

Pulgar (1975), geógrafo, abogado, doctor en letras, profesor universitario. Para mal, también político, lo que obnubiló lo científico sin reproche de su utopía. Como geógrafo, dejó establecido la nueva división geográfica longitudinal, según los pisos ecológicos: zona chala, yunga, quechua, suni, puna, janca, rupa rupa, omagua; como profesor dejó fundadas varias universidades en el Perú (Villarreal, Universidad Nacional del Centro, Hermilio Valdizán y Daniel Alcides Carrión) y uno en Colombia (Jorge Tadeo Lozano); por lo que mereció la condecoración de las Palmas Magisteriales con el grado de Amauta.
En 1975, participó en el proyecto de regionalización de las Fuerzas Armadas y actuó como político. Propuso las ocho regiones transversales para que cada región tenga costa, sierra, selva, mar y puertos y un sistema de redistribución de la producción. Modificado y discutido, fue su aporte para la Comisión Nacional de Regionalización de 1981, con el gobierno de Belaúnde. Los productos de cada piso longitudinal atravesado por una sola región serían aprovechados por los conrregionales, como si de eso se tratara la regionalización, como si los productos no fueran movilizados por el mercado. Del determinismo de Romero se pasa al intervencionismo voluntarista basado en la experiencia de los Purunrunas de dos mil años antes de Cristo y su costumbre de subir y bajar montañas, contra la tendencia histórica del sedentarismo a los costados de los cuerpos de agua y las rutas a curva de nivel.

De Haya de la Torre (1985), no pudo decir mucho sobre el tema. Tuvo mucho de político y poco de científico. Usó el relativismo de Einstein y el absolutismo de Marx y, a manera de un Joseph Knecht (personaje literario del Juego de Abalorios de Herman Hesse) y creó su propia teoría Espacio Tiempo Histórico (1936), por la que, entre otras ideas, la historia de Latinoamérica no debió considerar su inicio en 1492, sino antes. Creó su propio movimiento, la Alianza Popular Revolucionaria Americana en 1924 (APRA) y creó su propio partido, el Partido Aprista Peruano en 1930. Pensó en la formación de regiones por razones económicas, pero no tuvo idea de cómo formarlas; por eso invitó a Pulgar Vidal a su Partido, éste lo hizo y,en reciprocidad, Haya se afilió a la utopía de las regiones transversales, sus se- guidores seguirían la pauta, pero con seguridad, no tenían idea de si la propuesta era buena o mala; era suficiente y se afiliaron por disciplina y para siempre. Su megalomanía lo llevó a extender una utopía mayor el federalismo latinoamericano bolivariano, de visos tan impracticables en el presente como que, el primer intento, la Confederación Perú Boliviana, fue vencido por Chile al vencer a Santa Cruz en 1839 con ayuda de militares peruanos nacionalistas, como Ramón Castilla. El único "bolivarianismo" que hoy se pregona es el de Venezuela, de Hugo Chávez, que estudió en el Perú y tuvo no poca inspiración aprista y velasquista. A su seguidor, Alan García, le tocó proponer la primera regionalización (1985-90) y la mayor descentralización administrativa y fiscal (20062011), con tan graves consecuencias.

Andrés Tinoco Rondán (1982), aprista, siguió con el regionalismo transversal, pero olvidando el federalismo supranacional de Haya, sentenció: Argentina se considera la despensa del mundo y que se expandirá en Sudamérica hasta conformar en toda Latinoamérica, la Argentina Triangular. Si hoy supiera que la soya de la empobrecida y federal Argentina ha desaparecido a los gauchos y ha sustituido al ganado que daba de comer al mundo por la soya transgénica, daría cuenta de que ahora sólo es despensa de transnacionales de grano y aceite. Imaginar a Argentina, a la que se le hunden los barcos por falta de mantenimiento, invadiendo Brasil, es atrevido, como lo es otra de sus advertencias: Brasil considera que su límite natural son los Andes. La teoría expansionista de Tinoco fue materia de la tesis de maestría de otro seguidor aprista, César Zumaeta. Sin mayores consideraciones ecológicas, Tinoco considera 
que nuestra proyección desarrollista debe ser hacia la selva alta y selva baja, para aprovechar sus recursos, como si la Amazonía, de tierra joven y pobre tuviera más recursos que sus bosques, algunos suelos para plantaciones permanentes e hidrocarburos en parte de su subsuelo. Considera que cada región debe ser atravesada por amplias carreteras como paso obligado para la exportación de Brasil, por el Pacífico. Lo rescatable de Tinoco fuesu convicción de quelos departamentos no deben desintegrarse.

Efraín Gonzales de Olarte (1989), economista peruano, profesor de la Universidad Católica del Perú, desarrolló los conceptos de frontera económica (espacio incipientemente expresado en centros poblados que son $60 \%$ de pobres del Perú); frentes económicos, (exigen una administración pública propia); espacio regional, definido en las palabras de Frederica Barclay Rey de Castro (1995) como espacio donde la articulación de los antiguos frentes económicos y el avance de la frontera económica ha dado lugar a la existencia de un núcleo espacial ya estabilizado, con un alto grado de densidad económica, en el que predominan relaciones de tipo mercantil o en donde se ha generalizado en diversos grados los mercado de tierra, de trabajo, de bienes, de servicios y de capital. Comparte la idea de la integración regional y que la falta de integración es el problema del Perú porque las personas no se incorporan a las estructuras económicas e institucionales donde viven y actúan; pero con ello se refiere más a las vías que a la administración.

Sergio Boisier, economista y profesor de Alcalá de Henares hace reconocimiento implícito del reduccionismo de Chile, al reconocer que tenía salida al Atlántico y se fue reduciendo al per- der el Salar de Atacama, la provincia de Cuño y la Patagonia para ceder a lo que hoy es Argentina, lo que deja una pregunta obligada ¿Acaso Chile, antes medio continente y ahora menos de 800 mil Km2, es más que Argentina, Bolivia, Perú, precisamente porque administra un territorio menor? Nos dice que el regionalismo chileno nace en 1966, con Frei, pero preocupados más por la descentralización económica que la política y administrativa, reconoce que recién en 2013 se eligieron intendentes regionales por votación. Criticó la Constitución de Pinochet que declaró que las regiones no debían ser más de trece, lo que se modificó y dio lugar a las actuales quince, pero ya no quiere admitir el reduccionismo y confiesa pavor pánico a crear más regiones, que empezaron siendo once, luego se desagregó Cautín y fueron doce, y terminaron en quince, lo que confirma el reduccionismo. Reconoce el mismo problema de todos los países regionalizadores, con crecimiento económico sin desarrollo, que induce a pensar que la regionalización no está concebida con el enfoque correcto: la unidad de planificación.

El economista boliviano, asesor de la CEPAL, experto en desarrollo económico territorial, Finot (2001) asume como causa de la tendencia descentralista en la crisis del endeudamiento, lo que es una insinuación a que la descentralización es más por disciplina fiscal producto del Consenso de Washington, que por el interés del desarrollo regional, o sea, impuesto desde afuera; pero dice que también lo es por la ineficiencia del Estado patrimonialista, posesionario de la masa monetaria. Afirma que la descentralización y la regionalización tienen como origen a la corriente neoliberal y el libre mercado, es decir, descentralizar para crear competitividad del centro, reducir la pobreza y viabilizar la par- ticipación constructiva. Considera la necesidad de la recentralización en materia de salud y la educación, para no tener, por ejemplo, educación de primera, de segunda y de tercera según sea particular, particular subvencionado y estatal. Ello ya indica que la descentralización no ha estado orientada al desarrollo sino a las exigencias del mercado.

\section{Las teorías territoriales frente a las} nuevas tendencias

La globalización, “engloba”, pero no prescinde de los Estado-Nación, a los que no iguala, los diferencia cada vez más con brechas cada vez más amplias. Andrés Huguet en su blog (http://huguet.tripod.com/fukuyama. htm) advierte que, cuando se desarticuló la Unión Soviética y cayó el Muro de Berlín, dijo que la hegemonía capitalista y el predominio absoluto del liberalismo harán que en la sociedad post-histórica las luchas en gran escala entre estados desaparezcan con la 'mercadización común' de las relaciones internacionales. Sin embargo, por lógica, si cayeron los gobiernos socialistas, la globalización resulta capitalista; entonces, el capitalismo tiene necesidad existencial de competencia y competitividad; y para ello se necesita tener con quien competir, y éstos son los Estados-Nación. Los Estados Nación deben ser democráticos y autónomos porque no es posible inducir decisiones "globalizantes" en países que no tienen democracia ni autonomía. La globalización necesitó de igualar al mundo con un hecho técnico, la comunicación universal, para poder establecer un comercio más ágil y mantener las demás diferencias, como son los hechos financieros del dominio de cuatro monedas (Dólar, Yen, Euro y Renminbi - Yuan). Ello explica la persistencia de las diferen- 
cias Norte-Sur y centros-periferias. La globalización existe y se fortalece por la competitividad tecnológica, por eso es semánticamente imposible la expresión "globalización igualitaria", que sería como "igualdad competitiva", que son contradicciones en sus propios términos.

Al caer el poder de los Estados comunistas y su discurso pro social y triunfar el liberalismo, desaparece el rostro humanista del capitalismo: keynesianismo, Glass Steagal, etc., y vuelve a sincerarse (eliminación del patrón oro, el dólar como referencia internacional de valor, mercado especulativo, Banca de Inversiones, derogación del Glass Steagal, etc.) El mentido fin de la historia sólo es la aniquilación de ideologías por aniquilamiento de las organizaciones. En esa dialéctica, aparece el factor China”, dualidad perversa del capitalismo, conversión del capitalismo de Estado en comunismo capitalista. Dualidad de gobernabilidad sin gobernanza, economía de mercado de bienes y un mercado laboral barato y sin sindicatos. China adquiere una ventaja competitiva, que, siendo espuria, es conveniente y sostenible por su alianza natural con las transnacionales occidentales que disponen de sus mercados cautivos. China y su tsunami de inversiones obtiene gran crecimiento anual y grandes reservas de capital, capaz de detener la fuerza del dólar. Ahora, el hombre unidimensional de Marcuse (1985), antes reservada a los países industrializados es transversal por la tecnología y una producción industrial en escala y automatizada que permite el acceso a todos. La relación centro-periferia en todos los países del Sur, se manifiesta en ciudades ingobernables $y$ zonas rurales, que a decir de Andaluz (2010) viven con caos de ordenamiento territorial, instrumento madre de la gestión ambiental, con exceso de normas contradictorias y circulares, los hombres sobreviven sobre el caos y la degradación natural.

De este fenómeno global se puede verificar dos hechos contradictorios: uno, se requiere de la descentralización como propósito de desarrollo, pero su soporte no puede ser la competitividad de Porter, aplicable en actividades industriales; dos, una competitividad de estructura urbanoindustrial, deja al mercado el juego de sus libres fuerzas y éste ejerce una fuerza centrípeta que atrae las periferias hacia el centro. Por su propia semántica la competitividad nos coloca en una especie de condena fatal, la imposibilidad de poder competir con los "ganadores". Lo que nos lleva a la necesidad de desarrollar un concepto nuevo, la competitividad sistémica, un concepto que nos lleve a olvidar conceptos recursivos e inútiles como unidades geoeconómicas, transversalizar las regiones naturales, la integración de cuencas, espacios con economía de escala, corredores económicos, regiones federales de Alfonso Klauer (1999), etc., así como olvidar también la necesidad de crear regiones como entidades territoriales. Es necesario caminar a la descentralización sobre la base del ordenamiento territorial, el ordenamiento hídrico, el respeto a las aptitudes del suelo por su capacidad de uso mayor, la industrialización regional; pero para ello es necesario asumir la competitividad sistémica, única que puede ser territorial.

Jörg Meyer-Stamer (2004), alemán, fundador de la metodología Participación y Acción para la Competitividad Local- PACA, es un exponente inspirador de soluciones para el desarrollo territorial, la competitividad sistémica, única propuesta que genera ex- pectativas por el desarrollo territorial descentralizado cuando se expresa la descentralización como una realidad posible sin modificar la estructura productiva de un país primario exportador y con vínculos unidireccionales con las regiones respecto de su capital y las principales ciudades costeñas. Fue establecida por cuatro niveles de acción: El Nivel Micro, definido por componentes como los productores, los servicios al productor, el comercio, los consumidores. El Nivel Macro, donde el Congreso, las normas de seguridad jurídica, las medidas aduaneras, la política arancelaria, las instituciones estatales, el flujo de comercio internacional, el Banco Central el tipo de cambio, los órganos judiciales, Etc., generen estabilidad. El Nivel Meso, referido a políticas específicas de desarrollo de ventajas competitivas para las exportaciones, el desarrollo regional, el desarrollo de la infraestructura, competitividad agraria y desarrollo industrial, servicios públicos y el mejoramiento ambiental con ordenamiento territorial. Nivel Meta, referido al aprendizaje, modificación de organizaciones ante cambios sistema de valores individuales, diálogo, intercambio de información, reciprocidad, normas de autolimitación (ISO), sinergias, evitar errores advertidos, externalidades negativas, clientelismo, corrupción, etc.

Se sigue una estructura heurística como bien indica Vargas (2010), en su libro ¿Cómo hacer una investigación cualitativa? Una guía práctica para saber qué es la investigación en general y cómo hacerla. La investigación ha correspondido al tipo de investigación cualitativa, por lo que no parte de una hipótesis. El basamento ha sido la revisión literaria de diferentes autores que aludieron al tema desde diferentes perspectivas desde 1928 , 
por tomar como punto de partida a José Carlos Mariátegui relacionados al tema, complementado con entrevistas a diferentes funcionarios públicos de alto nivel aun cuando no hayan sido de la especialidad. El único autor relacionado al tema que aceptó la entrevista y la concedió fue Alfonso Klauer.

Tabla 4.

\section{Estructura Heurística}

Fuente: Xavier Vargas Beal. Del libro: ¿Cómo hacer una investigación cualitativa? Una guía práctica para saber qué es la investigación en general y cómo hacerla.

\begin{tabular}{ll}
\hline Cuestión. & De qué manera. \\
\hline Verbo. & mantienen validez \\
\hline $\begin{array}{l}\text { Objeto de estudio } \\
\text { teórico. }\end{array}$ & $\begin{array}{l}\text { los modelos de } \\
\text { regionalización y } \\
\text { descentralización }\end{array}$ \\
\hline Objeto de estudio & $\begin{array}{l}\text { en relación a } \\
\text { los modelos de } \\
\text { empírico. }\end{array}$ \\
$\begin{array}{l}\text { competitividad } \\
\text { regional }\end{array}$ \\
\hline Límite espacial. & en el Perú, \\
\hline Límite temporal. & bajo la influencia \\
& de conceptos \\
& desde 1928. \\
\hline
\end{tabular}

La realidad global en el marco del desarrollo territorial

Al establecerse que la globalización es una cobertura global de la tecnología de la información bajo un control de mando no globalizado y que dicha globalización no tiene relación alguna con la igualdad económica, pues los países altamente industrializados son muy diferentes a los que no lo son.

Por el contrario es un mecanismo necesario para una mayor diferenciación económica, fundamento de la competitividad; queda también establecido que los Estados-Nación no sólo no desaparecerán, sino que son dialécticamente convenientes en un mundo en el que las diferencias no deben ser impuestas sino autónomamente aceptadas, lo que hace importante la representatividad de los interlocutores, condicionados por el dominio financiero y tecnológico. En el dominio económico la diferencia fundamental está en la estructura productiva, en una polarización entre países territorialmente industrializados y países primario-exportadores. Hoy, si a ningún país le interesa dominar mediante la ocupación territorial ni existe la antes obligada relación entre dominio y extensión territorial; tampoco veremos a países dominantes dispuestos a aceptar la existencia de países fuera de su influencia, a costa de intervenciones forzadas bajo cualquier pretexto, aun cuando éste aparente ser humanista. La acción pública del sector privado ha convertido a las dictaduras en económicamente costosas y poco competitivas. En ese contexto, con una dialéctica perversa aparece el "factor China", de régimen dual de "capitalismo comunista" de abaratamiento espurio de costos de producción se ha convertido en una ventaja competitiva que preocupa a occidente.

En ese contexto, se verifica una contradicción entre la tendencia histórica de reducir espacios y la corriente dominante de crear regiones para sustituirlas. En el mundo desarrollado, las demarcaciones tienden a la igualdad y ser los núcleos espacialmente diferenciados de las que menciona De Olarte y las zonas económicamente fronterizas casi no existe.

Por su lado, desde el New Deal iniciado por Roosevelt, la teoría de la competitividad sistémica, a la que se refiere Meyer-Stamer, se manifestó desde que se ocuparon de la descentraliza- ción económica con acompañamiento del gobierno nacional en un proceso de crear empresariado regional con promoción del Estado, adopción de correctas medidas macroeconómicas y generando una cultura del desarrollo territorial con mercados propios y especializados. Ello como la verdadera forma de descentralizar.

La realidad latinoamericana y la descentralización

En Latino América aún se pretende que el expansionismo territorial es una amenaza internacional, aun cuando Chile está demostrando que con sólo 760 mil kilómetros cuadrados en proporcionalmente más que el resto de sus vecinos. De la misma manera, las pretensiones bolivarianas de integración han quedado tan desfasadas que el que lo intenta cae en desgracia, como el caso de Venezuela.

En relación a la creación de grandes demarcaciones con el nombre de regiones para reemplazar a las anteriores unidades mayores (departamentos, provincias, según el nombre que adopten los diferentes países), sólo es una forma de descentralizar el centralismo, pues aleja a los pueblos del interior de sus capitales y de la gestión administrativa, por eso, cuando Boisier sustentó la regionalización chilena con la reducción de 25 provincias y su propia Constitución estableció que éstas no deben ser más de trece regiones, lo que consiguió Chile es que la realidad se imponga y hoy ya estén en quince regiones; pues no es posible evitar que los pueblos desarrollen y se vayan convirtiendo en unidades geoeconómicas que se conviertan en núcleos con articulación propia al mercado. De la misma manera, cuando Finot manifiesta que se debe re-centralizar la educación y la salud 
para que haya ciudadanos de una sola condición y no de primera, segunda y tercera; lo que está diciendo es que la descentralización administrativa y fiscal que se está promoviendo en Latino América no conduce al desarrollo de manera automática sino que primero se tiene que producir la descentralización económica, fuerza motriz que exige las otras descentralizaciones. Parte de la realidad latinoamericana es el no reconocer que el centralismo es un fenómeno derivado de la condición de ser países de estructuras productivas primarios exportadoras que termina concentrando las poblaciones en las grandes ciudades y que la solución a ese problema no es la descentralización administrativa y fiscal sin descentralización económica, pensamiento que ha llevado al absurdo de proponer que la gente sea conducida donde está el agua y no el de conducir el agua donde están las tierras productivas y generando desarrollo industrial en las zonas donde menos tierras hay, como es el caso de la sierra de todos los países andino amazónicos, países en los que se sufre la deforestación como la más negativa de las manifestaciones de ese error político.

La realidad peruana en la descentralización económica

La regionalización eficaz es la de converger intereses comunes, pero no desaparecer los departamentos ni sus autonomías, es unirlas para lograr sinergias, con una primera preocupación, la descentralización económica, que no supone transferencias fiscales, sino desarrollo de sus capacidades industriales propias para incrementar su capacidades negociatorias. Si a la luz de los hechos dados y los años pasados, sometemos el pensamiento de Mariátegui a los parámetros de desarrollo actuales, habremos de convenir que el problema de la sierra peruana persiste, pero su solución ya no es una solución al problema del indio resolviendo el problema respecto del parámetro de la tenencia.

Hay nuevos parámetros actualmente imprescindibles en las aspiraciones de los campesinos, como la educación, el acceso a la salud, el acceso al mercado, las vías de comunicación, los medios de transportes, la telecomunicación, mecanización, productividad, formas de organización, etc. La Reforma Agraria de 1969 (Ley 17716) nos ha demostrado que la tenencia comunal no generó desarrollo y hay persistencia de los problemas de retraso socioeconómico. Así mismo, el modelo comunal se ha convertido en un problema contra la productividad por la mala calidad de los pastos, por la competencia intra-específica por el mismo pasto y la imposibilidad social de poder trabajar parcelas de mejoramiento de pastos debido a que nadie puede cercar tierras comunales que es de todos y de nadie a la vez. Bajo esa perspectiva socioeconómica, la modificación demarcativa con territorios excedidos a sus departamentos para formar regiones en una contradicción histórica de quienes negaban las intendencias y pretenden volver a regiones de esas mismas dimensiones; o la descentralización de competencias administrativas, fiscales o políticas, no tendrán impacto alguno sobre esa realidad, pues ninguno de esos factores podrá modificar positivamente creando descentralización económica en pueblos con modelos productivos preincaicos.

La historia ha demostrado que los departamentos de Francia en un números mayor a 90 para un país con la mitad de la extensión peruana o cómo están demarcados los Estados de Es- tados Unidos, verificamos que todas las demarcaciones son convencionales y obedecen a una decisión política, al margen de por qué se delimitó de una manera u otra. Los problemas económicos del interior y las propuestas de demarcación, hoy, han superados las a Mariátegui, Belaúnde, Basadre y Romero. La solución derivada de la propuesta de Romero de una política de poblamiento trasladando habitantes donde hay agua sin verificar si hay suelo, para imitar a los mitimaes incas, ha resultado depredatoria. Hoy, se lleva agua donde está la tierra seca. Por su lado la propuesta de Haya de la Torre y el federalismo internacional no tiene mayor asidero social ni responde a una necesidad y debe ser superada. Por último, la utopía de Pulgar Vidal queda desechada por la fuerza de los hechos, ya que las regiones naturales son longitudinales, el mercado tiene ruta transversal, pero las regiones convergen a las ciudades importantes de la costa, principalmente Lima, sin que ello convierta a Lima en parte de todas las regiones.

Es necesario converger en un modelo de descentralización con competitividad sistémica como única forma de general el desarrollo territorial nacional. Cuando los intelectuales nos atrevamos a reconocer que hay que modificar la secuencia: problema del indio - problema de la tierra - problema de la tenencia hacendaria - distribución comunal, que ya ocurrió y que no modificó el problema socioeconómico del campesino y la sustituyamos por la secuencia: problema de la sierra - problema de las tierras escasas - problema de la improductividad de la tierra - incremento de la población campesino-comunal - disminución de tierras por habitante - degradación ecológica creciente de los pastizales altoandino - imposibilidad comunal 
de parcelación para mejora gradual de pastos - salto de campesino a agricultor - industrialización de la sierra - migración planificada llevando agua donde están las tierras secas"; estaremos en condiciones de proponer concertada y participativamente una solución al verdadero problema socioeconómico del país, problema que no se está solucionando con la descentralización administrativa, fiscal y política. Por el contrario sólo está dando muestras de degradación, ya no de la tierra, sino de la condición humana.

\section{DISCUSIÓN}

Sin duda, lo que hemos venido creyendo como verdad ha sido, muchas veces, ha dependido de quien lo diga, no de quien la tenga. Los propios políticos, como fue el caso de Haya de la Torre, de tan poco tener idea de lo que debía ser la demarcación territorial en el Perú, invitó a que lo proponga quine él creyó que era el mejor para hacerlo, sin advertir que sería el menos indicado, Javier Pulgar Vidal. Ello se debe a que ha actuado en la mente de todos un falso principio que lo motivó al error, creer que la demarcación territorial, por ser trazos ideales en un territorio, es una materia que obedece a técnica y que éstas responden a la ciencia de la geografía. Al parecer, nada más lejos de la verdad. Por la experiencia global, se ha visto que si Francia, creador del modelo, se divide en más de 90 departamentos y se unen en un Estado unitario, sobre un territorio de algo más de la mitad del que posee el Perú; que Suiza con 41 mil kilómetros cuadrados, posee 26 cantones y se reúnen en una confederación y que Estados Unidos con 9,9 millones de kilómetros cuadrados y se reúne en un modelo de Estado federado con 50 estados, divididas en línea rectas, etc. Es obvio que creer que se trata de una decisión científica y de rigores técnico metodológicos, se tratará de llamar al mejor; pero no existe ni una ciencia ni una técnica de demarcación territorial, ésta la determina la historia particular de cada país, y su resultante, es aceptada por un convencionalismo político. La fuerza de ciertas creencia, como el de la demarcación por cuencas, corredores económicos o unidades geoeconómicas, puede ser tan fuerte que no logra hacer discernir que funciona para unos y no para otros; así, una macrocuenca puede atravesar varios departamentos e inclusive países y no por ello determinar una demarcación, o, las márgenes de un río unas veces unir, como aquellos pequeños pueblos, y otras dividir, como el Putumayo nos divide de Colombia. Lo mismo, en los países económicamente centralistas, "todos los caminos conducen a Roma", con lo que estamos diciendo que todos los caminos conducen a Lima o las otras ciudades costeñas, y las regiones no pueden formarse superponiendo los mismos centros. Las unidades geoeconómicas son dinámicas y las demarcaciones no pueden modificarse a su ritmo. No requiere mayor explicación el tema de los expansionismos territoriales latinoamericanos frente al expansionismo económico, como el que ejerce Chile sobre sus países vecinos con su poca extensión territorial. De manera que las teorías de grandes territorios como fundamento de desarrollo y competitividad ha perdido vigencia

La descentralización es una expresión necesariamente vinculada a su opuesto, el centro. No es concebible pensar en la descentralización sin pensar en una relación centro-periferia; es decir, para que conceptualmente exista una, debe existir la otra y ambos son necesarios. Si la descentralización es trans- ferir, se requiere del transferente, pero no que éste desaparezca, pues nunca dejará de ejercer la rectoría de los actos descentralizados. El establecimiento de una autonomía descentralizada con desaparición del centro, no es descentralización, es la creación de un país independiente. Si la descentralización tiene las variables administrativa, fiscal, política y económica; cada una tiene funciones, mecanismos y limitaciones propias. La administrativa, entrega funciones, la fiscal, entrega recursos; la política, entrega poder. La única descentralización que no se entrega es la económica, pues ella genera autarquías territoriales dentro de un marco de complementariedades. Un espacio que crea un gran núcleo de producción agrícola la tiene como suya, no como transferida; si crea industria, comercio, turismo, etc., siempre quedan como creaciones propias. Y es en eso en lo que consiste la descentralización económica como finalidad de toda descentralización y manera de generar equilibrio con las demás. Por ello, no es sostenible la idea de que la descentralización consiste en una transferencia cuantitativa de funciones, recursos y poder a las autonomías territoriales si no se verifica el desarrollo de capacidades para ejercerlas y desarrollo económico propios.

En el esfuerzo de la descentralización económica, el camino se endereza hacia la competitividad sistémica del desarrollo territorial con convergencia entre el Estado, la empresa, la sociedad y la cultura económica empresarial con una visión de lo local, sin pérdida del movimiento económico global. Sin políticas a nivel macro, dirigidas al desarrollo regional según la complementariedad de sus potencialidades para interesar al mercado, no es posible el desarrollo competitivo de las regiones. Sin políticas a nivel 
micro, dirigidas a la promoción del desarrollo empresarial productivo de las pequeñas y microempresas bajo modelos promocionales de organización empresarial y el circuito de la cadena productiva, no será posible dicho desarrollo competitivo regional, aun cuando cuente con toda la descentralización administrativa, fiscal u política. Sin políticas a nivel meso, referido a políticas específicas de desarrollo de ventajas competitivas para un mercado interesado, el desarrollo de la infraestructura vial, educativa, sanitaria, de salud, eléctrica, la competitividad agraria, la derivación industrial y el mejoramiento ambiental con ordenamiento territorial; no será posible el desarrollo económico. Sin políticas de nivel meta, referidas al aprendizaje espontáneo e informal de empresa, la modificación de paradigmas organizacionales ante cambios del sistema de valores, la modificación de la cultura del refugio en lo colectivo para desarrollar iniciativas individuales surgidos de una nueva actitud económica; el diálogo e intercambio de información entre pares y entre agentes con intereses contrapuestos de la cadena productiva; actitudes de reciprocidad sinérgica, normas de autolimitación mediante códigos de ética, autocensura, modelos (ISO), experiencias ajenas para tratar de evitar errores advertibles, externalidades negativas, clientelismo, corrupción, etc.; si ello, tampoco será posible la competitividad regional y su desarrollo económico.

\section{REFERENCIAS BIBLIOGRÁFICAS}

Andaluz, A. (2010). La dimensión jurídica del ordenamiento territorial. Documento Técnico $N^{\circ} 1$. Santa Cruz: FCBC Editorial.

Barclay, F.\& Santos, F. (1995). Órdenes $y$ desórdenes de la Selva central. Historia y economía de un espacio regional. Lima: IEP Ediciones.
Basadre, J. (1994). Perú: Problema y Posibilidad. (4ta ed.). Lima: Editorial Fundación M.J. Bustamante de la Puente.

Belaúnde, V. (1931). La Realidad Nacional. París, Francia: Le livre Libre

Finot, I. (2001). Descentralización en América Latina: teoría y práctica. Santiago de Chile: CEPAL.

Haya, V. (1985). Obras completas de Víctor Raúl Haya de la Torre. Lima: Editorial Juan Mejía Baca

Huamaní, P., Bautista, E.\& Bonilla, L. (2011). La gerencia social y la rentabilidad social: El caso de la Comunidad Campesina de Huayocondo-Ayacucho. Revista de Investigación de la Facultad de Ciencias Administrativas. 14(28), 69-85.

Klauer, A. (1999). Descentralización: Sí o Sí. Lima: Full Print SRL.

Maletta, H. (1980). Cambios en el Perú rural desde 1950. En Centro de Investigación y Capacitación (Ed), La realidad del campo peruano después de la Reforma Agraria. Diez Ensayos críticos (17- 65). Lima, Perú: Editora Ital Perú.

Mariátegui, J. (1968). 7 Ensayos de interpretación de la realidad peruana. Lima, Perú: Biblioteca Amauta.

Marcuse, H. (1985). El Hombre Unidimensional. Ensayo sobre la ideología de la sociedad industrial avanzada. Obras Maestras del Pensamiento Contemporáneo. México: Planeta.

Spanhi, C. (1971). Semblanza de los pueblos del Perú. Homenaje al sesquicentenario de la Independencia del Perú 1821-1971. Lima: Peruano Suiza.

Tinoco, A. (1982). Regionalización. APRA. Descentralización regional. Comisión Nacional de Plan de Gobierno del Partido Aprista Peruano. Lima: Pueblo.

Vivanco, W. (2011). Por qué y cómo hacer la revolución ganadera en los Andes. Revista Agro Noticias, Año XXXIII, 371.

Boisier, S. (2004). Desarrollo territorial y descentralización. El desarrollo en el lugar y en las manos de la gente. Revista eure. 30(90), 27 - 40.

Hardin, G. (1968). The tragedy of the Commons. Science. (162), 1243-1248. DOI: 10.1126/science.162.3859.1243

Meyer-Stamer, J. (2004). Participación y Acción para la Competitividad Local (PACA): Impulsando Iniciativas para el Desarrollo Económico Local. Recuperado de http://www.mesopartner. com/uploads/media/mp-wp1_PACAespanol_01.pdf

Tito, P., Bautista, E. y Bonilla, L. (2011). La gerencia social y la rentabilidad social: el caso de la comunidad campesina de Huayacondo - Ayacucho. Gestión en el Tercer Milenio. 14(28), 69-86.

Vargas, X. (2010). ¿Cómo hacer una investigación cualitativa? Una guía práctica para saber qué es la investigación en general y cómo hacerla. ITESO. Recuperado de https://es.scribd.com/ doc/48098212/Como-hacer-investigacion-cualitativa-LIBRO-DE-TEXTO 